\title{
O ENSINO JURÍDICO DESDE O BRASIL IMPERIAL E A NECESSIDADE DE UMA REFORMULAÇÃO PARA MELHORIA DA QUALIDADE DE APRENDIZAGEM
}

\author{
THE LEGAL TEACHING SINCE THE BRAZILIAN IMPERIAL PERIOD AND THE \\ NEED FOR A REFORMULATION FOR IMPROVING THE QUALITY OF LEARNING
}

\author{
Caroline Rodrigues Calloto Dante ${ }^{1}$ \\ Fabrizia Angelica Bonatto Lonchiati ${ }^{2}$
}

\section{RESUMO}

O presente trabalho busca, por meio da pesquisa bibliográfica, abordar a necessidade da reformulação do ensino jurídico para melhoria da qualidade de aprendizagem. Para tanto, faz uma abordagem histórica do estudo Direito e sua visão atual, com a finalidade de demonstrar a crise existente. Promove um estudo do ensino jurídico dentro do sistema e sua avaliação e busca demonstrar a necessidade da pesquisa do Direito como forma de ensino. Igualmente, apresenta a eficácia do estudo jurídico, no sistema conhecido como Aprendizagem Baseada em Problema, com o intuito de incentivar a participação do aluno, na busca do pensamento reflexivo e crítico.

Palavras-chave: História do Direito; Ensino jurídico; Reformulação; Melhoria; Estudo por problemas.

\section{ABSTRACT}

This article has as scope, by means of a bibliographical research, explore an approach to reformulating legal education to improve the quality of learning. For this, it takes a historical analysis to the study oi Law and its current view, in order to demonstrate the existing crisis. Promotes a study of legal education within the system and its evaluation and seeks to demonstrate the need for law research as a form of teaching. Also, it presents the effectiveness of the legal study, in the system known as , Problem-based Learningin, with the objective of to encouraging student's participation in the search for reflexive and critical thinking.

Keywords: History of Law; Legal education; Reformulation; Improvement; Study from problems.

\footnotetext{
${ }^{1}$ Bacharela em Direito pela Universidade Estadual de Maringá (2013); Pós-graduanda em Direito do Trabalho e Previdenciário pelo Instituto de Direito e Cidadania-IDCC (2015-2016); Mestranda em Ciências Jurídicas Centro Universitário Cesumar - UNICESUMAR (ingresso em 2016), Maringá - PR (Brasil). E-mail: carol_celloto@hotmail.com

${ }^{2}$ Mestranda do programa de Mestrado em Ciências Jurídicas pelo Centro Universitário de Maringá. Pós graduanda em Direito Processual Civil pelo Centro Universitário Internacional; Pós-graduada em Direito Aplicado pela Escola de Magistratura do Paraná; Graduada em Direito pela Pontifícia Universidade Católica do Paraná (Brasil).
} 


\section{INTRODUÇÃO}

O presente trabalho tem como finalidade promover reflexões acerca da necessidade reformulação do ensino jurídico como salvaguarda para melhoria da qualidade de ensino, sendo dividido em quatro capítulos.

Para tanto, no primeiro capítulo, tece breve histórico do ensino jurídico no Brasil, assim como, do panorama atual, pelo qual se verifica que o ensino da ciência jurídica sempre foi motivo de preocupação do Estado e sociedade, o que tem motivado diversas reformas, desde o Decreto Imperial de 11.08.1827.

Na sequência, realizar-se-á uma análise quanto ao ensino jurídico dentro do sistema, bem como, a necessidade de uma avaliação mais efetiva, visando a melhoria da qualidade de ensino educacional brasileiro. Isso porque, o cenário atual aponta para uma crise educacional, que está atrelada à ausência de formação de pensadores, que, por sua vez, decorre da fragmentação do Direito, da ausência de incentivo somada à proliferação exacerbada de faculdades ou cursos de Direito no País, sem que haja uma fiscalização, de maior verticalidade, quanto à qualidade do ensino praticada.

O terceiro capítulo demonstra a importância da pesquisa do Direito como forma de ensino e aprendizado, demonstrando que a ausência de incentivo à pesquisa jurídica adequada tem refletido na formação de profissionais, o que aponta grandes dificuldades na atuação prática do Direito.

Diante deste cenário, é patente a necessidade de reformulação do ensino jurídico de forma precisa e de grande amplitude. É preciso, pois, uma análise, da forma que se pratica o ensino jurídico como um todo, capaz de fazer uma correlação dentre as disciplinas jurídicas e não uma análise meramente fragmentada. Impõe-se, por conseguinte, uma modificação da matriz curricular, buscando modernizá-la com os novos Direitos, apontando, nesse sentido, a importância de um ensino jurídico em conformidade com o método da Aprendizagem Baseada em Problemas, pois sempre possibilita a formação de melhores profissionais. Tal método prioriza a análise de casos práticos, com a finalidade de incentivar o profissional a pensar o Direito como um todo fazendo uma correlação, inclusive com as outras ciências correlatas.

Trata-se, referida análise crítica, do quarto e último capítulo. 


\section{BREVE HISTÓRICO DO ENSINO JURÍDICO E CONSIDERAÇÕES ACERCA DO PANORAMA ATUAL}

A fim de possibilitar discussão futura, no presente trabalho, acerca da necessidade de reformulação do ensino jurídico, atualmente praticado, assim como, à correlação de tal necessidade diante da formação de profissionais qualificados, impõe-se uma breve análise da história do ensino jurídico no Brasil e consequente apontamento sobre o que pode melhorar no panorama atual.

Os primeiros cursos do ensino jurídico no Brasil surgiram, aproximadamente, cinco anos, após, a independência do Brasil, por meio de Lei promulgada em 11.08.1827, subscrita por d. Pedro I e o Visconde de São Leopoldo. Nesse momento, foram instituídos os dois primeiros cursos de Direito no Brasil, denominados “Academias de Direito", em São Paulo, cujo curso fora instalado no Convento de São Francisco, e em Olinda, no Mosteiro de São Bento. Cumpre mencionar que, em 1854, passaram a ser intituladas de "Faculdades de Direito", sendo nesse momento, igualmente, que o curso de Olinda fora transferido para Recife.

Não se pode perder de vista que a finalidade de tais cursos era a formação de juristas e intelectuais brasileiros, a fim de que estes ocupassem cargos na administração pública do Estado Imperial, que havia sido recém-criado (RODRIGUES, 1988, p. 19). Desta feita, outra conclusão não há senão a de que o acesso a tais cursos restringia-se aos integrantes das altas classes sociais, conforme aponta Roberta Teles Bezerra (BEZERRA, 2008, p. 65) e, ainda, de cunho masculino:

Estes primeiros momentos da história já demonstravam o que o ensino jurídico representaria no Brasil, um estudo voltado exclusivamente para a elite e para viabilização dos seus interesses. Consequentemente um estudo voltado a traduzir a ideologia política dominante - o liberalismo, e tinha por fim a manutenção do status quo da monarquia e da burguesia, esta, representada no Brasil pelos grandes proprietários de terra.

Com tal finalidade, verifica-se que, no período do Império, os cursos jurídicos eram totalmente controlados pelo Governo Central, de forma centralizada, havendo controle tanto dos recursos, quanto dos currículos, metodologia de ensino, nomeação dos professores (lentes) e diretor, programas de ensino e das obras a serem estudadas. 
Cumpre mencionar que a partir deste período (Império) começou-se a abandonar as ideias jusnaturalistas, passando-se a evoluir o pensamento positivista.

Com a República, houve patente reforma no ensino jurídico, podendo-se destacar a reforma ocorrida em 1891, tendo como um de seus idealizadores Rui Barbosa. Referida reforma possibilitou a expansão dos cursos, pois permitira a criação de faculdades livres, ou seja, instituições particulares de ensino. Com o aumento de cursos, se possibilitou o acesso da classe média ao ensino superior. Houve, igualmente, modificação do currículo jurídico, inserindo disciplinas propedêuticas de cunho humanístico, tais como, Sociologia e Filosofia (LIMA in ARAÚJO, 2010, p. 35) e retirando o ensino eclesiástico.

Posteriormente, em 1931-1932, ocorreu a Reforma de Francisco Campos, que tinha por escopo inserir caráter eminentemente técnico profissionalizante aos Cursos de Direito, ocorrendo o desdobramento do Bacharelado e do Doutorado. A ideia era que, primeiro se formassem profissionais, para, em seguida, preparar os futuros professores e pesquisadores da área.

Em meados de 1955, San Tiago Dantas, defendia uma reforma no ensino, que, segundo ele, teria como meta o treinamento e o efetivo desempenho do raciocínio jurídico, uma vez que defendia um movimento de restauração da supremacia da cultura jurídica, assim como, da confiança no Direito como forma de controle social (DANTAS in Encontros da UnB, p. 52).

Já em 1962, houve uma tentativa para reforma dos currículos mínimos, porém, na prática não houve mudanças substanciais, pois os cursos mantiveram-se limitados. Em seguida, em 1972, por intermédio da Resolução n. 03, do Conselho Federal da Educação, institui-se currículo mínimo, na qual houve patente flexibilização do mesmo, cujo objetivo seria a adaptação ao mercado de trabalho e às realidades locais e regionais, tendo vigorado até 1994.

Em 1994 foram realizadas mudanças substanciais no ensino jurídico, através da Portaria n. 1.886/94 do Ministério da Educação (MEC), que trouxe, dentre outras alterações, a expansão da carga horária dos cursos de direito para 3.000 horas, assim como, a obrigatoriedade do estágio supervisionado e a realização da monografia jurídica como requisito da graduação. Estabeleceuse, ainda, currículo mínimo, composto de disciplinas de outros ramos, como, por exemplo, sociologia, economia e ciência política. Desta feita, admitiu-se que “[...] a formação do intérprete deveria abranger aspectos culturais e não simplesmente ficar limitada ao conhecimento de normas" (BEZERRA, 2008, p. 82). 
Em seguida, em 1996, publicou-se a Nova Lei de Diretrizes da Educação, qual seja, a

Lei n. 9.394/1996, que dispõe sobre o ensino fundamental, médio e superior no Brasil.

Destaque-se, igualmente, a Resolução n. 9, do Conselho Nacional de Educação e Câmara de Educação Superior, ressalta a relevância das disciplinas de cunho humanístico e propedêutico, isto é, incentivam a interdisciplinaridade, conforme artigo $3^{\circ}$.

Importante, mencionar, por fim, o Decreto n. 5.773/2006, dispõe no artigo 28 , § $2^{\circ}$, que o Conselho Federal da Ordem dos Advogados do Brasil deverá se manifestar sobre a criação de cursos de direito.

Tal medida se fez necessária diante da proliferação dos cursos de direito, característica do atual panorama do ensino jurídico no Brasil.

Sobre o tema, importante trazer a baila o posicionamento do doutrinador Manoel Cipriano Oliveira, que aponta que os cursos de direito nos últimos tempos foram criados, de forma desmedida:

\begin{abstract}
Visando mais o interesse comercial do ensino pelas instituições privadas do que a qualidade na prestação educacional, apresentado docentes, cujo comportamento contribui para a má formação dos futuros profissionais. O que tem contribuído para a frustação daqueles que ingressam nos cursos jurídicos, acreditando no Direito como meio de materialização do ideal de justiça. (OLIVEIRA, 2001, p. 181).
\end{abstract}

Tal cenário, segundo posicionamento atual, denota crise no ensino jurídico, diagnosticado por uma crise educacional. Sobre a questão, assim continua se manifestando o doutrinador acima mencionado, afirmando que no campo do direito reside:

Conteúdo programático de baixa qualidade, uma vez que não prepara o futuro jurista para o mercado de trabalho, estando abaixo do nível exigido para aprovação em concursos e para o ingresso inicial nas carreiras públicas federais, estaduais e municipais, e, até mesmo, para obter aprovação para inscrição definitiva, junto à Ordem dos Advogados do Brasil. (OLIVEIRA, 2001, p. 181).

Restou, portanto, traçado breve retrospecto do ensino jurídico, que, à luz do atual cenário, denota uma crise educacional, conforme se abordará a seguir, que, culmina, na necessidade de uma reformulação do ensino jurídico.

\title{
3 O ENSINO JURÍDICO DENTRO DO SISTEMA E SUA AVALIAÇÃO
}


Em diapasão ao disposto no tópico anterior, necessário se faz um aprofundamento acerca do ensino jurídico dentro do atual sistema brasileiro, assim como, a avaliação atualmente exercida sobre tal ensino.

Inicialmente, cumpre esclarecer que o ensino jurídico não pode ser confundido com o conceito de educação. Educação é o "processo de desenvolvimento da capacidade física, intelectual e moral da criança e do ser humano em geral, visando à sua melhor integração individual e sociais [...] Aperfeiçoamento integral de todas as faculdades humanas". (AURÉLIO, 2004) .

Infere-se, desta feita, que educação é gênero do qual o ensino jurídico é espécie. Isso porque, da análise conceitual em conjunto com o teor do art. $1^{\circ}$, da Lei ${ }^{\circ}$ 9.394/1996, conclui-se que a educação é permanente, já que incluiu a sociedade, bem como, a própria vida do indivíduo, seja no ambiente familiar, profissional ou social, estando, portanto, em constante transformação. Por outro lado, o ensino jurídico deve ser examinado como dinâmico enquanto processo social. Desta feita, é imperioso que transmita esse dinamismo, seja no âmbito conceitual, seja na prática, pois deve contribuir para a construção de um programa de civilização.

É possível, por conseguinte, conceituar ensino como "a transmissão de conhecimentos, informações ou esclarecimentos úteis ou indispensáveis à educação ou a um fím determinado; [...] esforço orientado para a formação ou modificação da conduta humana". (AURÉLIO, 2004).

Sobre o assunto - distinção entre educação e ensino - Haidt aponta que "a educação pode se processar tanto de forma sistemática como assistemática, o ensino é uma ação deliberada e organizada" (HAIDT, 2003, p. 12).

Quanto ao Direito, não é possível perder de vista, que se trata de uma ciência eminentemente social, uma vez que possui como objeto as relações sociais, tendo por escopo solucionar problemas práticos dos seres humanos (MONTEIRO, 2001, p. 42).

Inegável, portanto, a importância do ensino jurídico, pois:

O ensino não se qualifica em si mesmo, mas em relação a uma sociedade mais ampla com determinados valores, padrões de comportamento, modelos de referências e expectativas. O conhecimento dessa realidade abrangente poderá fornecer parâmetros para a medição da qualidade que se almeja implementar. (MACIEL, 1995, p. 92). 
Corroborando, salienta o doutrinador Maciel, que "o ensino não se qualifica em si e por si mesmo, mas em relação a uma sociedade mais ampla com determinados valores, padrões de comportamento, modelos de referências e expectativas" (MACIEL, 1995, p. 92).

Outro ponto que merece destaque é em relação aos modelos de ensino jurídico. Sobre a questão, imperioso mencionar a lição do professor Doutor José Sebastião de Oliveira (OLIVEIRA, 2003, online), que aponta, basicamente, três tipos, abaixo elencados.

O primeiro modelo de ensino jurídico seria o modelo cultural ou humanístico, no qual se ensina a pensar e criar o Direito, porém, não busca a solução de casos e problemas, logo não possui relação estreita com o direito processual. Em segundo, elenca o modelo profissionalizante ou técnico informativo, que visa à formação do jurista como mero operador do Direito, possuindo, portanto, postura positivista. Por fim, em terceiro, refere-se ao modelo mistonormativo ou de formação integral, segundo o qual se busca a formação de um jurista integral, com forte formação humanística no início do curso, assim como, forte formação profissional no final do curso. Para o autor, por conseguinte, o terceiro modelo seria o ideal para ser adotada para os nossos cursos jurídicos.

Compete, deste modo, aos professores, incentivar os alunos a perceberem que o curso de Direito impõe leitura, estudo e reflexão, não perdendo de vista que o sistema precisa ser compreendido em sua globalidade. Veja-se a lição de Aguiar sobre o tema:

A experiência docente nos cursos jurídicos tem mostrado um fenômeno assustador: o desvanecimento do vigor, do interesse, da curiosidade e da indignação dos alunos, na razão direta de seu avanço no curso. No início, seus olhos brilham, sua curiosidade é aguda, suas antenas estão ligadas para o que acontece no mundo, chegando a assumir posições políticas transformadoras. Aos poucos, na medida em que galgam outros patamares do curso, passam a se ensimesmar, a perder seu afã transformador, abordando a informalidade criativa e adotando uma indumentária padronizada, uma linguagem estandardizada, marcada por uma retórica ultrapassada, sendo seus sonhos abandonados e substituídos por desejos curtos de passar em concursos ou pertencer a exitosas bancas de advogados para ganhar dinheiro e conquistar a tão decantada segurança burguesa. Seus olhos já não tem mais brilho, sua criatividade desapareceu como habilidade de urdir soluções novas, pressupostos diferentes e teorias transformadoras. (AGUIAR, 2004, p. 186).

Diagnostica-se, desta feita, uma crise no ensino jurídico, já que o professor-jurista ao se limitar à exegese do Direito posto, ou seja, não incentivando a crítica e o pensamento reflexivo, apresentando meramente um sistema pronto e acabado, não orienta os alunos a buscarem o 
porquê das determinações, levando a um distanciamento da realidade, bem como, a uma fórmula positivista reducionista (FARIA, 1987, p. 28).

No mesmo sentido leciona Ferraz Jr.:

É preciso reconhecer que, nos dias atuais, quando se fala em Ciência do Direito, no sentido do estudo que se processa nas Faculdades de Direito, há uma tendência em identifica-la com um tipo de produção técnica, destinada a atender as necessidades profissionais (o juiz, o advogado, o promotor) no desempenho imediato de suas funções. $\mathrm{Na}$ verdade, nos últimos cem anos, o jurista teórico, pela sua formação universitária, foi sendo conduzido a esse tipo de especialização fechada e formalista. (FERRAZ JR., 1994, p. 49).

Outro fator agravante da crise atualmente instaurada, deve-se, conforme já mencionado, à proliferação dos cursos de Direitos, pois, embora tenha importância social (maior acesso da população ao ensino), acabou por reforçar o afastamento da teoria e a proximidade com a prática forense, já que

A estruturação pedagógica atrasada, as aulas ministradas em salas lotadas, a pouca exigência acadêmica condenam esses cursos ao papel de formadores de despachantes, que operam perifericamente com as normas, usando seu fraco bom senso, já que não tratam os comandos normativos com um mínimo de rigor. (ENCARNAÇÃO, 1995, p. 114).

Diante desse cenário de enfraquecimento jurídico, diagnosticado pelo sistema de ensino atualmente adotado, corroborado pela proliferação dos cursos de direito, que, por vezes, visam mais o interesse comercial do ensino do que a qualidade do serviço educacional prestado, é inegável a importância da avaliação, seja em relação à abertura de novos cursos, seja avaliando os cursos já existentes.

Isso porque, a avaliação institucional é considerada impulsionadora de mudanças, seja no processo acadêmico de produção, seja na disseminação de conhecimento, que refletirá, por conseguinte, na formação de cidadãos e de profissionais, desta feita trata-se de meio hábil para motivar a transformação do ensino superior.

Para tanto, criou-se em 2003, o Sistema Nacional de Avaliação da Educação Superior (SINAES), através da Lei n. 10.861/2004, cujas finalidades, dentre outras, nos termos do artigo $1^{\circ}, \S 1^{\circ}$, é a melhoria da qualidade da educação superior e o aumento da efetividade acadêmica e social. 
Todas as instituições de ensino superior são avaliadas pelo INEP, a fim de que seja apurada a qualidade da mesma. Os instrumentos utilizados para a produção de indicadores de qualidade, assim como, de processos de avaliação dos cursos são o Exame Nacional de Desempenho de Estudantes (ENADE) e as avaliações que são realizadas in loco pelas comissões de especialistas, conforme esclarecimentos existentes no próprio sítio eletrônico do INEP.

Imperioso destacar, igualmente, que a avaliação é realizada em três âmbitos/momentos distintos, que são: para autorização, para reconhecimento e para a renovação do reconhecimento.

$\mathrm{Na}$ atualidade, a Ordem dos Advogados do Brasil tem interferido, diretamente, no processo de autorização, reconhecimento ou credenciamento dos cursos de Direito, pois a ela compete emitir parecer favorável ou desfavorável a abertura dos mesmos. Tal necessidade está expressa no já citado Decreto 5.776/2006, assim como, no artigo 54, XV, do Estatuto da OAB (Lei n. 8.906/1994). A interferência da Ordem dos Advogados do Brasil outro objeto possui, senão o de contribuir na qualidade do ensino jurídico oferecido pelas instituições.

Desta feita, resta demonstrada a importância da avaliação dos cursos já existentes, bem como, na abertura de novos cursos, diante do cenário do ensino jurídico-educacional brasileiro, atualmente existente, sendo necessário, ainda, reestruturação no sistema, conforme se passará a demonstrar.

\section{A PESQUISA DO DIREITO COMO FORMA DE ENSINO}

Como visto no tópico anterior, há que se falar, na atualidade em uma crise educacional, causada, em especial, pela forma em que se está ministrando o ensino jurídico. Nesse viés, bem assevera Rizzatto Nunes: "a escola de Direito tem problemas, e dentre eles um dos mais relevantes é de ordem pedagógica: o ensino oferecido tem peculiaridades tais que, muitas vezes, faz com que se duvide, inclusive, se se está ensinando algo" (NUNES, 2005, p. 1).

Portanto, imperiosa uma mudança na forma de ensino, tal qual o incentivo à pesquisa jurídica, com maior verticalidade, item de abordagem no presente tópico.

Isso porque, o incentivo à pesquisa jurídica traduz um dos melhores métodos para se associar ideias novas com o conhecimento a ser adquirido pelos discentes. Tal realidade é possível através da construção de grupos de trabalho e de grupos de discussão, sempre sobre a 
mediação e intervenção do professor. Desta feita, estar-se-á promovendo a discussão e o debate, gerando o entrosamento entre os acadêmicos e os docentes acerca do tema posto em debate, para o qual se busca o aprofundamento do conhecimento.

É possível, inferir, por conseguinte, que é imprescindível a leitura e a discussão para a formação de bons de profissionais, uma vez que aproxima a teoria e a legislação da realidade social, além de propiciar ao estudante a possibilidade de efetivar pesquisas, o que faz com o que mesmo conheça as verdadeiras características da área profissional onde, futuramente, irá atuar. (DALLARI, 2007, p. 31).

Importante mencionar que o fenômeno da proliferação dos cursos jurídicos também atingiu os cursos de pós-graduação, porém tal aumento não refletiu na melhoria da formação dos profissionais do Direito, pois o aumento qualitativo não acompanhou o aumento quantitativo.

Há que se falar, em verdade, em um atraso qualitativo, que, segundo Nobre, está fundamentado em duas premissas:

A minha hipótese é que esse atraso está ligado a dois fatores fundamentais. Em primeiro lugar, o isolamento em relação a outras disciplinas das Ciências Humanas e uma peculiar confusão entre a prática profissional e pesquisa acadêmica. É da combinação destes dois fatores que irá resultar uma relação extremamente precária com as disciplinas das Ciências Humanas, como na concepção de o que é objeto da Ciência do Direito. (NOBRE, 2005, p. 24).

Corrobora Fragale e Veronose dizendo que o atraso qualitativo está relacionado a um problema de viés metodológico e epistemológico, que, para eles, seriam ainda mais presente do que a precária institucionalização apontada por Nobre. Referidos doutrinadores assim se manifestam:

Parece-nos que o real "atraso", não percebido por Nobre em sua reflexão, consiste na ausência de uma reflexão epistemológica e metodológica mais consistente na área jurídica. Esse nos parece ser o grande handicap da área e que necessita ser urgentemente enfrentado, sob pena (para usarmos uma lógica típica do direito positivo) de continuarmos à margem do sistema nacional de pós-graduação, ainda que respondendo por um importante contingente de seus programas e cursos e de suas populações docente e discente. (FRAGALE e VERONESE, 2004, p. 67).

Desta feita, sustenta-se a importância da pesquisa jurídica na formação dos profissionais, assim como a necessidade de se repensar a pesquisa já desenvolvida. É preciso, pois, propostas 
que se preocupem com empiria e com a interdisciplinaridade, assim como, com a visão epistemológica, nas quais se reconheça o Direito como fenômeno dinâmico intimamente relacionado com o fenômeno social.

Nesse viés, afirma o doutrinador Nobre que “[...] se quisermos implantar um modelo novo de pesquisa, a primeira coisa que devemos fazer é exigir uma dedicação integral à pesquisa, ao ensino e à extensão de uma parte substancial dos docentes de um curso de Direito" (NOBRE, 2005, p. 36-37).

Ocorre que, o ensino jurídico deficiente, somado à ausência de pesquisa jurídica eficiente, adequada, bem realizada, afeta diretamente a atuação dos profissionais formados nesse sistema. Tais consequências são sentidas desde a dificuldade em se encontrar espaço no mercado de trabalho até a alienação do jurista, que denotará a má atuação do profissional.

Isso porque, quando o bacharel ingressa no mercado de trabalho e passa a atuar como advogado, não terá aptidão para atender as necessidades sociais e até mesmo jurídicas, pois o discurso proferido nas faculdades não se coaduna com a prática (GALUPPO, 2009, p. 4634).

Tal realidade pode ser sentida também quando o aluno formado for atuar, por exemplo, na magistratura. É o que aponta Dalmo de Abreu Dallari:

Com esses tipos de preparo um aluno que opte, por exemplo, pela magistratura, terá grande dificuldade quando for obrigado a utilizar uma conceituação jurídica básica, para confrontar um texto com os fatos e circunstâncias da realidade social, procurando a solução jurídica e justa para um conflito. E como são muitos os cursos que utilizam essa metodologia, existem boas razões para que se diga que cabe muita responsabilidade às escolas de Direito por deficiências de profissionais das áreas jurídicas, inclusive magistrados. (DALLARI, 2007, p. 31).

Ora, inegável, portanto, diante desse cenário, que a crise da educação, acentuada pela ineficácia da pesquisa jurídica atualmente desenvolvida nos cursos jurídicos, tem afetado o desempenho dos profissionais do Direito, assim como, a correta a aplicação do direito. Oportuna, nesse momento, a lição de Horácio Wanderlei Rodrigues, que afirma que "precisa-se, com urgência, de um Direito de vida e de uma educação efetivamente comprometida com ela" (RODRIGUES, 2005, p. 22).

Impõe-se, por conseguinte, a reformulação do ensino jurídico, que deve ser analisado de forma complexa, discussão esta que será abordada no próximo tópico. 


\section{REFORMULAÇÃO DO ENSINO JURÍDICO DE FORMA COMPLEXA E A IMPORTÂNCIA DO ESTUDO DO DIREITO POR PROBLEMAS}

Como já abordado nos itens acima, o ensino jurídico brasileiro tem sofrido crises constantes ao ponto de formar profissionais aplicadores do Direito e não pensadores com a finalidade de buscar a justiça ao caso concreto.

Por esta razão, é imprescindível que o ensino jurídico sofra uma modificação complexa e dentro deste contexto, tem-se o ensinamento de Edgar Morin que assim disciplina:

É o problema universal de todo o cidadão do novo milênio: como ter acesso às informações e organizá-las? Como perceber o Contexto, o Global (a relação todo/partes), o Multidimensionalismo, o Complexo? Para articular e organizar os conhecimentos e assim reconhecer e conhecer os problemas do mundo, é necessária a reforma do pensamento. [...]. A esse problema universal confronta-se a educação do futuro, pois existe inadequação cada vez mais ampla entre os saberes fragmentados, desunidos, divididos, com as realidades ou problemas cada vez mais multidisciplinares, globais. (MORIN, 2000, p. 35-36).

Analisar o ensino jurídico de forma fragmentada, por matérias, como é proposto no sistema brasileiro, é ir à contramão do pensamento jurídico social ao ponto de restringir a atuação do profissional do Direito à aplicabilidade de leis, que nem sempre são adequadas ao caso concreto. Este modelo de ensino faz com que os profissionais se limitem em averiguar um problema apenas na seara jurídica, sem que haja uma contribuição para a evolução da sociedade.

José Eduardo Faria ao escrever sobre o ensino jurídico menciona acerca da gravidade do ensino fragmentado: "trata de um ensino em densidade teórica e sem rigor lógico-formal, que se destaca pelo senso comum normativista, pela reprodução de uma vulgata positivista e pelo recurso a uma erudição ligeira e retórica, subserviente aos clichês e estereótipos dos manuais". (FARIA, 1993, p. 54).

Dessa forma, o ensino jurídico deve ser visto como um todo e capaz de fazer uma correlação entre as disciplinas jurídicas, de tal forma que se consiga enxergar, por exemplo, o direito constitucional dentro do direito do consumidor. Todavia, esta correlação jurídica não é auto suficiente, haja vista que a ciência jurídica tem o condão de estabelecer padrões sociais, inclusive de condutas. Assim, indispensável que haja um estudo da ciência jurídica com a economia, com a política, com o avanço tecnológico, dentro outros. 
É esta visão complexa que o jurista deve adquirir ao adentrar no estudo da ciência jurídica com o fim de se construir uma sociedade mais justa e ética.

Por esta razão, necessário se faz, antes da análise do texto positivado, o estudo da filosofia e da sociologia, ao ponto de se buscar a essência do direito positivado. Esse estudo fará com que o pensador do direito consiga identificar os princípios e os costumes do local a ponto de se buscar, não só a aplicação do direito posto, mas principalmente, os ideais de justiça.

Ora, o jurista não pode ser considerado mero aplicador do Direito, mas sim um aplicador da Justiça. Esse é o pensamento de João Batista Villela:

[...] reduzir o ensino jurídico a uma iniciação na arte e técnica de resolver conflitos de interesse na sociedade constitui, no fundo, uma visão pobre e até negativista do próprio direito. Com todas as reservas que contra ele podem ter, é, entretanto, o judicialismo que se pratica quando nas faculdades o ensino não vai além de indicar aos alunos a regra material que o Estado prevê para conflitos tipo [...] e o consequente caminho para sua efetivação pelo juiz. E mais uma vez é o judicialismo que se pratica quando as faculdades, para assegurar treinamento a seus alunos, criam e mantém serviços ditos de assistência judiciária, com total indiferença pra com outras formas de realização do Direito. E finalmente o judicialismo que se pratica quando não se reconhece como direito senão aquilo que foi declarado tal pelos tribunais e com o que, sob a capa de realismo, se submetem os valores humanos à variação e relatividade dos julgamentos individuais. (VILLELA, 1974, p.42-44).

Ensinar o profissional do Direito tão somente a interpretar os dispositivos normativos do ordenamento jurídico é impedir um avanço legislativo, uma vez que a legislação posta não é capaz de acompanhar, cronologicamente, a evolução social.

Dessa forma, o ensino do Direito pode ser realizado sob duas perspectivas: "a primeira através do conhecimento e da análise da legislação vigente no Estado e a outra através da compreensão do próprio Estado". (NADER, 2003, p.97).

Este modelo seria o ideal para o ensinamento da ciência jurídica, já que além do estudo do Direito da forma como se encontra nas leis (direito positivado), estuda a realidade social, o contexto em que essa norma foi legislada, bem como se o direito posto está em conformidade com o contexto social atual. Diante desse modelo ideal, verifica-se a necessidade da mudança curricular do ensino jurídico, com a finalidade de se buscar um pensador do Direito diante do caso concreto. 
Atualmente, as aulas ministradas durante a graduação do ensino jurídico apostam no padrão expositivo e que possui o condão de demonstrar o direito posto como solução para os conflitos sociais. Todavia, esta visão de ensino está longe de ser ideal.

Necessário se faz a estimulação do pensamento, para isso, é imprescindível que o ensino incuta no estudante da ciência jurídica, um valor, um comportamento, capaz de enxergar os padrões sociais. Nesse sentido, tem-se o ensinamento de Aurélio Wander Bastos:

Não se pode desvincular o ensino do Direito, enquanto proposta juridicamente consolidado de compreensão e percepção da vida, da própria vida. Da mesma forma, o ensino do Direito não pode estar dissociado da sua própria ocorrência judicial; também não pode dissociar-se da sua ocorrência social, sob pena de os tipos legais se desvincularem das figuras reais. O estudante de Direito não pode ser levado a entender o Direito como uma abstração sem referencias práticas - academicismo, ou uma prática sem referencias conceituais - o burocratismo. Se o primeiro dissocia o ensino jurídico da sua ocorrência social e judicial, o segundo o separa da sua dimensão reflexiva, e as duas dimensões, conjuntamente, impedem o seu desenvolvimento integral. (BASTOS, 1998, p. 293).

O doutrinador ainda descreve acerca da necessidade do ensino jurídico por meio de casos práticos com a finalidade de instigar o pensamento da ciência jurídica

O desenvolvimento e o aprimoramento do ensino jurídico não podem privilegiar a dogmática e desprezar a pragmática e o método de pensar e ensinar o Direito. As proposições curriculares devem estar vinculadas às proposições metodológicas de ensino, sendo imprescindível que os programas sejam desenvolvidos através de modelos de ensino discursivo, por problemas, por casos ou por verificação documental, como forma especial de se ensinar a pensar e a fazer (pragmática). O modelo de ensino não deve estar dissociado da sua proposição preliminar: ensinar o aluno a pensar os códigos e os fatos juridicamente significativos, nunca a pensar apenas com os códigos. $\mathrm{O}$ desprezo ao método como forma de pensar, de ensinar e de aprender é uma das causas fundamentais do aquisolamento, não só do ensino jurídico, como também do processo interpretativo e do conhecimento da pragmática do Direito. Nas aulas não se deve privilegiar o domínio dos códigos, deve-se ensinar a marcha e os métodos para alcançálos (BASTOS, 1998, p. 294).

Diante desta análise, entende-se que o ensino jurídico deve ser baseado em problema, adotando, por conseguinte, o método da Aprendizagem Baseada em Problema (ABP): uma metodologia de ensino implantada, primeiramente, no curso de Direito de Harvard (EUA) e, posteriormente, em outas universidades de sistema do Commow Law, e já adotada por algumas faculdades de Direito em nosso País. 
Este método de ensino prioriza o estudo por meio da análise de casos práticos e dentro de pequenos grupos chamados de tutorial. Arnoldi e Oliveira afirmam que este método é: "uma coleção de problemas cuidadosamente construídos e entrelaçados, apresentados a pequenos grupos de estudantes" (ARNOLDI, 2002, p. 53) que deverão discutir a "teoria, definição legal e jurisprudência responsável pela tarefa-problema" (ARNOLDI, 2002, p. 53).

A importância desta metodologia é a participação do aluno nas aulas ao ponto de construir um conhecimento geral não para se buscar, tão somente, uma solução para o problema apresentado pelo tutor, mas sim uma resposta para a questão estudada. Para isso o aluno terá de buscar o direito posto, a doutrina, as jurisprudências e até mesmo a visão sociológica e filosófica de tal forma que se concretizará a interdisciplinaridade do Direito.

Nesse encaminhamento, tem-se o ensinamento de Carlini:

O objetivo da ABP é permitir que o aluno, durante o curso e após a conclusão, consiga construir conhecimento por si mesmo. Por isso é que esse paradigma não se baseia na transferência do conhecimento, mas no desenvolvimento da capacidade do aluno de buscar as informações que serão necessárias para o desenvolvimento de sua atividade profissional, de modo a permitir sua permanente atualização a mudanças. A proposta é desenvolver um aluno-pesquisador para que ele se torne um profissional-pesquisador. (CARLINI, 2004, p. 16).

Esta sistemática está intimamente atrelada ao que o doutrinador Pedro Demo chama de autoridade de argumento:

[...] quem argumenta busca o debate, não sua conclusão, a mudança de perspectiva, não o fechamento, novos horizontes, não a mesmice [...]. Argumentar é jogo aberto e produtivo; não se esgota na tertúlia, diatribe ou exaltação, mas no confronto bem feito de teorias e práticas, com o objetivo de avançar no conhecimento; [...] A autoridade do argumento presta-se a acolher a diversidade infinita dos seres humanos, porque não se prende à autoridade, mas ao argumento, reconhecendo o direito de expressão própria de todos. (DEMO, 2005, p. 40/41 e p. 66).

Para este doutrinador a pesquisa e a construção do argumento são cruciais para o aprendizado:

[...] Desde cedo, torna-se absolutamente importante que as crianças descubram, a autoridade do argumento, afastando-se do argumento da autoridade. Em vez de um ambiente monitorado linearmente de fora para dentro e de cima para baixo, é decisivo construir ambientes de aprendizagem marcados pela esfera pública da discussão bem fundada e desimpedida. Assim fazendo, os alunos não só aprendem a reconstruir 
conhecimento, à medida que exercitam a arte de bem argumentar, contra argumentar, escutar com atenção, responder civilizadamente, estudar e produzir em equipe, colaborar com consensos possíveis. (DEMO, 2005, p. 93).

Reestruturando o currículo do ensino jurídico a partir desta prática, não será necessário o esgotamento de toda a normativa do direito posto, haja vista que o profissional terá o condão de pensar, em qualquer área específica do Direito, pois foi ensinado a pesquisar a ciência jurídica diante do caso concreto.

Assim, a atual dificuldade enfrentada pelo operador do Direito: lidar com os problemas que transcende o Direito, será encarada com maior facilidade.

\section{CONCLUSÃO}

A análise histórica do ensino jurídico no Brasil demonstra que a crise educacional, ainda existente, está longe de ser solucionada. Todavia, resta imprescindível a reestruturação deste com a finalidade de salvaguardar uma melhoria do ensino jurídico.

O ensino superior do Direito, da forma como é ministrado hodiernamente no Brasil é deficitário, pois criador de um profissional aplicador da lei e não de um jurista filósofo-pensador, capaz de enfrentar os problemas advindos de uma sociedade em constante modificação.

Deve-se atentar que o ensino superior da ciência jurídica possui o condão de enfrentar os problemas práticos e reais de uma sociedade. Isso porque, o modelo ideal para o ensino da ciência jurídica pressupõe o estudo da realidade social em conjunto com o contexto em que a norma fora criada, assim como, se o direito posto se coaduna com o contexto social atual.

Ocorre que, o ensino jurídico, na forma em que é imposto na atualidade, caminha em diapasão oposto, pois não há incentivo à pesquisa jurídica, agravando-se a situação por meio da proliferação de cursos jurídicos, que atualmente já passam de 1.200 (um mil e duzentos) cursos em todo o País, nos quais, por vezes, condiciona-se o estudo a salas lotadas, com pouca exigência acadêmica, além da estrutura curricular desconexa com a realidade social brasileira.

É, preciso, pois, uma avaliação efetiva dos cursos jurídicos, seja na abertura de novos cursos, seja fiscalizando os cursos já existentes, a fim de que seja preservada e/ou reestruturada a qualidade do ensino jurídico. 
De fato, imperiosa, como restou demonstrado, uma reestruturação do ensino jurídico, pois somente através de uma reformulação complexa, será possível possibilitar que o operador do Direito lide com problemas que transcendem o Direito, principal dificuldade enfrentada pelos nossos acadêmicos da área jurídica.

Por conseguinte, infere-se que apenas com o incentivo à pesquisa da ciência jurídica diante do caso concreto, isto é, cujo método priorize a análise de casos práticos, no qual se imponha que o aluno busque o direito posto, em compasso com a análise doutrinária, jurisprudencial, restará concretizada a interdisciplinaridade do Direito, dentro de um contexto da atualidade e da modernidade.

Isso porque, tal medida formará aplicadores, não apenas de Direito, mas também da Justiça, o que refletirá, inevitavelmente e futuramente, no desempenho do labor deste profissional, nas carreiras jurídicas, estando, desta feita, intimamente ligado à preservação dos interesses da sociedade, que são assegurados mediante a resposta ética e justa que do Poder Judiciário se espera.

\section{REFERÊNCIAS}

AGUIAR, Roberto A. R. de. Habilidades: ensino jurídico e contemporaneidade. Rio de Janeiro: DP\&A, 2004.

ARAÚJO, Régis Frota (org.). Metodologia do Ensino Jurídico: propostas e debates. Fortaleza: ABC, 2010.

ARNOLDI, Paulo Roberto Colombo; OLIVEIRA, Jaqueline Robeiro. Ensino jurídico baseado em tarefa-problema. In: Pratica jurídica, Editora Consulex, 2002.

BASTOS, Aurélio Wander. O ensino jurídico do Brasil. Rio de Janeiro: Lumen Juris, 1998.

BEZERRA, Roberta Teles. Ensino Jurídico e Direitos Fundamentais. Fortaleza: Expressão, 2008.

BRASIL. DECRETO N. 5.773 DE 9 DE MAIO DE 2006. Disponível em: <http://portal.mec.gov.br/seed/arquivos/pdf/legislacao/decreton57731.pdf>. Acesso em: 26 de março de 2016.

BRASIL. LEI N. 8.906, DE 4 DE JULHO DE 1994. Disponível em: <http://www.planalto.gov.br/CCIVIL_03/leis/L8906.htm>. Acesso em: 26 de março de 2016. 
BRASIL. LEI N. 9.394 DE 20 DE DEZEMBRO DE 2006. Disponível em: < http://www.planalto.gov.br/ccivil_03/leis/L9394.htm>. Acesso em: 26 de março de 2016.

BRASIL. LEI N. 10.861 DE 14 DE ABRIL DE 2004. Disponível em: <http://www.planalto.gov.br/ccivil_03/_ato2004-2006/2004/lei/110.861.htm>. Acesso em: 26 de março de 2016.

CARNILI, Angelica. Aprendizagem baseada em problema e o ensino jurídico no Brasil: reflexões sobre a viabilidade desse novo paradigma. In: Anuário da Abedi, ano 2, 2004.

DALLARI, Dalmo de Abreu. O poder dos juízes. 3 ed. São Paulo: Saraiva, 2007.

DANTAS, San Tiago. A educação jurídica e a crise brasileira. In: RAMOS, Guiomar Feitosa de Albuquerque Lima (org.). Encontros da UnB: Ensino Jurídico, Brasília-DF: UNB, 1979.

DEMO, Pedro. Argumentação de autoridade $\mathbf{x}$ autoridade do argumento - interfaces da cidadania e da epistemologia. Tempo Brasileiro, 2005.

ENCARNAÇÃO, João Bosco da. A questão do ensino jurídico. In: ENCARNAÇÃO, João Bosco da. MACIEL, Getulino do Espírito Santo (Org.). Seis temas sobre o ensino jurídico. São Paulo: Cabral editora, 1995.

FARIA, José Eduardo. A função social da dogmática e a crise do ensino e da cultura brasileira. In: Sociologia Jurídica. Crise do Direito e Práxis Política. Rio de Janeiro: Forense, 1984, p. 184.

Mudar cenários e substituir paradigmas teóricos. In: Conselho Federal da OAB. OAB Ensino Jurídico: parâmetros para elevação de qualidade e avaliação. Brasília: Conselho Federal da OAB, 1993.

FERRAZ JR, Tércio Sampaio. Introdução ao Estudo do Direito: técnica, decisão e dominação. 2 ed. São Paulo, Atlas, 1994.

FRAGALE FILHO, Roberto; VERONESE, Alexandre Kehrig. A pesquisa em Direito: diagnóstico e perspectivas. RBPG. Revista Brasileira de Pós-Graduação, Brasília (DF), v. 2, p. 53-70, 2004.

GALUPPO, Marcelo Campos; FALEIROS, Thaisa Haber. A formação do docente em Direito: uma identidade desejada. Anais do XVIII Encontro Nacional do CONPEDI, 2009. Disponível em: <http://www.conpedi.org.br/manaus/arquivos/anais/maringa/Maringa_integra.pdf>. Acesso em: 26 de março de 2016.

HAIDT, Regina Célia Cazaux. Curso de didática geral. 7 ed. São Paulo: Ática, 2003.

INEP. Disponível em: < http://www.inep.gov.br/>. Acesso em: 26 de março de 2016. 
MACIEL, Getulino do Espírito Santo. Por um ensino jurídico crítico. In: ENCARNAÇÃO, João Bosco da. MACIEL, Getulino do Espírito Santo (Org.). Seis temas sobre o ensino jurídico. São Paulo: Cabral editora, 1995.

MONTEIRO, Geraldo Tadeu Moreira. Metodologia da pesquisa jurídica: manual para a elaboração e apresentação de monografias. Rio de Janeiro, 2001.

MORIN, Edgar. Os sete saberes necessários à educação do futuro. Trad. de Catarina Eleonora F. da Silva e Jeanne Sawaya. 2 ed. São Paulo: Cortez, DF: UNESCO, 2000.

NADER, Paulo. O ensino jurídico e o perfil dos concursos públicos. Ensino Jurídico OAB: Formação jurídica e inserção profissional. Brasília: Conselho Federal da OAB, 2003., p. 95-99.

NOBRE, Marcos; et. al. O que é pesquisa em Direito? São Paulo: Quartier Latin, 2005.

NUNES, Rizzatto. Manual de introdução ao estudo do direito: com exercícios para a sala de aula e lições de casa. 6 ed. rev. atual. e ampl. São Paulo: Saraiva, 2005.

OLIVEIRA, José Sebastião de. O perfil do profissional do Direito neste início do século XXI. Revista Jurídica Cesumar-Mestrado, marigá, vol. 3, n.1, ano 2033, Disponível em: <http://periodicos.unicesumar.edu.br/index.php.revjuridica/article/view/388/393>.Acesso em 04 abril 2016.

RODRIGUES, Horácio Wanderlei. Ensino Jurídico: saber e poder. São Paulo: Acadêmica, 1988.

. O ensino do direito, os sonhos e as utopias. In: RODRIGUES, Horácio Wanderlei (Org.). Ensino Jurídico para que(m)? Florianópolis: Fundação Boiteux, 2000, p. 15-33.

VERBETE Educação. In: NOVO Dicionário Aurélio. Curitiba, PR: Grupo Positivo, [2004]. CdRom.

VILLELA, João Baptista. Ensino do Direito: equívocos e deformações. Educação: Brasília, MEC, a. 3, n. 12, p. 40-48, abr./jun. 1974. 